\title{
Supratotal Resection of Periventricular Glioblastomas and Pathomorphological Rationale for Extensive Removal of Subventricular Zone
}

Artem V. Rozumenko ( $\sim$ dr.rozumenko@gmail.com )

Romodanov Neurosurgery Institute https://orcid.org/0000-0003-0668-6659

Valentyn M. Kliuchka

Romodanov Neurosurgery Institute

Volodymir D. Rozumenko

Romodanov Neurosurgery Institute

Tatyana A. Malysheva

Romodanov Neurosurgery Institute

Alao 0. Oluwateniola

Romodanov Neurosurgery Institute

Zoja P. Fedorenko

Romodanov Neurosurgery Institute

\section{Research Article}

Keywords: Periventricular glioblastoma, Subventricular zone, Supratotal resection, Pathomorphology

Posted Date: November 30th, 2021

DOI: https://doi.org/10.21203/rs.3.rs-1062097/v1

License: (c) (i) This work is licensed under a Creative Commons Attribution 4.0 International License. Read Full License 


\section{Abstract}

The aim of the research was to reveal the pathomorphological patterns of periventricular glioblastoma (PVG) dissemination and assess the rationale for extended surgical removal of subventricular zone (SVZ) as a step towards supratotal resection.

A total of 54 patients ( 16 females and 38 males, mean age $48.9 \pm 13.4$ years, range $22-69$ ) with PVG were prospectively included in the study. Standard preoperative evaluation included an MRI using 3D T1 with Gd-enhancement, T2, and T2-FLAIR series. The neuronavigation system was used to identify the SVZ and to remove of ventricular wall, additionally to image-guided total tumor resection. The pathomorphological assessment of PVG features with the description of the SVZ and changes in perifocal brain matter was performed by two pathologists.

The median Karnofsky Performance Scale (KPS) score raised from 67.8 to 81.9 in the postoperative period. The overall median survival was $13.0 \pm 2.7$ months. The low postoperative KPS score $(p=0.05)$ and basal ganglia invasion $(p=0.008)$ significantly decreased survival rates.

Microscopically, the typical multilayer structure of SVZ was disrupted. The invasive spread of tumor cells in thesubventricular space was identified. The ependymal layer had prominent dystrophic alterations of cells and destruction of intracellular connections. The hyperplastic reaction on neoplastic process was typical for adjacent ependyma.

The pathomorphological identification of periventricular glioblastoma invasion in the subependymal space supports the supratotal tumor resection with removal of adjacent SVZ as a potential source for relapse.

\section{Introduction}

Glioblastomas remain the most common primary malignancies of the brain among adults with high levels of disability, poor quality of life and low survival rates. Despite implementing unified protocols for combined treatment, the early relapse with multifocal dissemination causes an unfavorable prognosis in patients with high-grade gliomas $[6,22]$. According to the latest data, gliomagenesis is a process that starts in the subventricular zone (SVZ), which is considered a source of polypotent progenitor cells [1, 23]. In addition, distinct anatomical contact with the ventricular wall could be observed both in primary diagnosed periventricular glioblastomas (PVG) and, as well as in recurrent glioblastomas of other locations $[7,13,17]$.

The influence of a wide extent of glioma resection on survival rates supports the supratotal cytoreduction of PVG that implies removal of the perifocal area within the abnormal FLAIR signal and accomplished with the formation of porencephaly $[10,15,18,20]$. However, the pathomorphological features of tumor cells revealing their migration in the SVZ area and their distinctive relapse role are still not clarified. 
The study aimed to reveal the pathomorphological patterns of PVG dissemination and assess the rationale for extended surgical removal of the SVZ as a step towards supratotal resection.

\section{Materials And Methods}

\section{Patient population}

All consecutive patients with PVG operated from August 2018 to June 2020 were prospectively selected. The inclusion criteria were as follows: (1) age $\geq 18$ years, (2) newly diagnosed supratentorial glioblastoma (WHO grade IV), (3) periventricular tumor location. Exclusion criteria were as follows: (1) multifocal tumor, (2) history of any other malignant tumor and (3) incomplete clinical and neuroimaging datasets. A periventricular tumor location was defined as tumor invasion or distinct contact with the lateral wall of the lateral ventricles that corresponds to the SVZ. Pure intraventricular tumors were excluded.

Follow-up data were obtained retrospectively on patients visits and from the National Cancer Register of Ukraine. The study was performed in accordance with the 1964 Helsinki Declaration and approved by the Institutional review board.

\section{Imaging studies}

Standard preoperative evaluation included an MRI using 3D T1-weighted with Gd-enhancement, T2weighted, and T2-FLAIR series. In addition, the extent of tumor resection was evaluated within $24 \mathrm{~h}$ of surgery using an MRI with Gd-enhancement or an MSCT within $12 \mathrm{~h}$ of surgery, followed by an MRI for radiotherapy planning 3 weeks after.

\section{Surgical procedure}

3D surgical planning and image-guided resection were performed using Medtronic StealthStation navigation system (Minneapolis, USA). The tumor volume suitable for safe resection was outlined preoperatively. At least 3 foci for biopsy in the SVZ and perifocal white matter were marked on 3D planes. The appropriate surgical trajectory and patient head position were selected virtually. Craniotomy was performed in standard fashion; subcortical tumor resection was accomplished without the assistance of spatulas and retractors.

Total resection of contrast-enhanced tumor tissue was performed with neuronavigation control. The neuronavigation system was used for the SVZ localization and resection with forming of porencephaly. Further removal of the SVZ with adjusted white matter was performed to achieve supratotal resection.

\section{Histopathological assessment}

The main tumor tissue sample and harvested subventricular biopsies were forwarded to the institutional department of neuropathology and then observed by two pathologists. All samples were fixed in $10 \%$ 
buffered formalin and paraffin embedded. The paraffin microslides were stained with hematoxylin-eosin and hematoxylin-picrofuxin. The whole tissue samples were screened to assess the presence of subependymal infiltration zone, solid tumor areas, necrosis and vascular microproliferates.

Resected tumors were classified neuropathologically according to the WHO classification of tumors of the central nervous system (2016).

\section{Data collection and analysis}

Prospectively collected data set for each patient included demographic (age, sex), clinical (pre- and postoperative KPS score) and neuroimaging (tumor location and size, contralateral extension, septum contact and dislocation, intraventricular extension, presence of hydrocephalus) variables.

For continuous variables, descriptive statistics was used. The chi-square test and Pearson correlation were applied to compare distributions of categorical variables, and McNemar test was used to compare the related groups.

Overall survival (OS) was estimated by the Kaplan-Meier method using the log-rank (Mantel-Cox) test. OS was calculated as a function of time for the period from histological diagnosis onset until death or last follow-up. The multivariate analysis of the Cox hazard proportional model was performed to evaluate the covariates affecting outcomes. A p value of $<0.05$ was considered significant.

Statistical analysis was performed using the Deducer package (Java GUI extensions to statistical programming platform $\mathrm{R}$ licensed under the GNU).

\section{Results}

\section{Clinical outcomes}

A total of 54 patients ( 16 females and 38 males with mean age $48.9 \pm 13.4$ years, range $22-69$ ) who met the selection criteria were prospectively included in the study. Most of the patients were 45 and older -38 (70.4\%) cases. The median KPS score was 67.8 and the number of patients with KPS score more than 70 was in $34(63.0 \%)$ cases.

PVG were preferably located extraventriculary in 37 (68.5\%) patients. The larger diameter of the tumor (> $50 \mathrm{~mm})$ correlated with basal ganglia invasion $(p<0.01)$, hydrocephalus $(p=0.01)$, and contralateral side extension $(p=0.02)$.

The total removal of contrast-enhanced tumor with the SVZ resection accomplished by forming of porencephalia was confirmed by postoperative neuroimaging.

All patients were carried to clinic on the day of surgery, bypassing the ICU. There were no neurological and local complications during the short postoperative period. All patients got verticalization on the second day after operation. The regression of hypertension syndrome was observed in all cases. In the 
postoperative period the median KPS score raised from 67.8 to 81.9 , and the number of patients with KPS score more than 70 increased from $34(63.0 \%)$ to $47(87.0 \%)$ with $p<0.01$.

The follow-up data were available for 43 (79.6\%). The Kaplan-Meier analysis showed that overall median survival was $13.0 \pm 2.7$ months. The Cox proportional hazards modeling revealed that tumor basal ganglia invasion (HR 3.87, 95\% $\mathrm{Cl} 1.49-21.37 ; p=0.011$ ) and low postoperative KPS score (HR 3.35, 95\% $\mathrm{Cl} 1.01-11.23 ; p=0.05)$ significantly decreased survival rates. Demographic and clinical characteristics of patients, and surgical outcomes, are summarized in Table 1.

Table 1 Demographic and clinical characteristics of series. 


\begin{tabular}{|lll|}
\hline Variable & Value (\%) & p value \\
\hline No. of patients & $54(100.0)$ & \\
\hline Age at diagnosis (years) & & \\
\hline Mean & $48.9 \pm 13.4$ & \\
\hline Range & $22-69$ & \\
\hline$\geq 45$ & $38(70.4 \%)$ & 0.03 \\
\hline Sex & & \\
\hline Male & $38(62.1)$ & \\
\hline Female & $16(37.9)$ & 0.03 \\
\hline Preoperative KPS score & & \\
\hline Median & 67.8 & $<0.01$ \\
\hline$\geq 70$ & $34(63.0)$ & $<0.017$ \\
\hline Postoperative KPS score & & \\
\hline Median & 81.9 & $<0.01$ \\
\hline$\geq 70$ & $47(87.0)$ & \\
\hline Tumor characteristics & & $<0.01$ \\
\hline Extraventricular location & $37(68.5)$ & $<(15.2)$ \\
\hline Septum dislocation $\geq 10 m m$ & $62(40.7)$ & 0.17 \\
\hline Septum contact & $22(47.7)$ & 0.60 \\
\hline Contralateral side extension & & \\
\hline Basal ganglia invasion & $37(70.5)$ & $<0.01$ \\
\hline Hydrocephalus & & \\
\hline Largest diameter $>50 m m$ & & \\
\hline & & \\
\hline
\end{tabular}

Characteristics of pathomorphological material

Fifty-four sets of pathological tissue specimens were microsurgically collected. For each patient, at least three types of pathological zones in the resected tissue were microscopically distinguished: solid proliferating tumor, perifocal zone of infiltration (tumor border and edematous white matter diffusely infiltrated by tumor corresponds with FLAIR-abnormality area), and the SVZ (ependyma with the subependymal area). 


\section{Solid tumor}

All solid tumor specimens were morphologically verified as glioblastomas. Classical signs of WHO grade 4 glioma such as prominent nuclear atypia with high mitotic activity (pathologic mitoses and high (> $10 \%$ ) proliferative index), foci of palisading necrosis and microvascular proliferation were identified in all cases. The hemorrhagic and cystic components were common. The primitive ependymal rosettes were presented directly in the subependymal area (Fig. 1), forming concentrically arranged cell clusters without vessel association (Fig. 2).

\section{Perifocal area}

The perifocal area was presented with edematous changed axons invaded by glioma cells. Density and compactness of axons decreased in the direction to the main tumor mass. The area of identified tumor invasion was narrower than the edema zone. The perifocal edema zone also included signs of neovascularity with glomerular proliferation of endothelium, local demyelination and axonotomia, disruption blood-brain barrier, as well as structure and micro- and macroglial polymorphism. Dystrophic reactive changes were also found in the subependymal areas outside of the tumor proliferation and invasion zone (Fig. 3)

\section{Subventricular zone}

The typical multilayer structure of SVZ was disrupted. The ependyma had dystrophic alterations of cell and destruction of intercellular junctions. The hyperplastic reaction to neoplastic process was typical for adjacent ependyma. The invasive spread of tumor cells in the subventricular space was identified (Fig. 4).

The stroma of hypocellular layer had signs of glioma invasion. The depth of tumor infiltration corresponded with hypocellular layer density. The astrocytic and transitional zones had the typical characteristics of solid glioblastoma with the prevalence of anaplastic glial cells (Fig. 5).

\section{Discussion}

According to the available data from the national cancer registries, the incidence of brain malignancies is growing steadily worldwide. The incidence of glioblastomas in the United States reaches $3.20(95 \% \mathrm{Cl}$ $3.17-3.23$ ) per 100,000 population, which is $14.6 \%$ of all CNS tumors, and more than half of all primary malignancies of the brain. At the same time, the prevalence of glioblastoma in the population is only 9.23 per 100000 compared to the prevalence of primary malignant tumors of the CNS (47.6 per 100000 ). This disproportion is caused primarily by extremely low survival rates of patients with glioblastomas $[4,6,19,22]$.

The aggressive nature of glioblastoma biological behavior with high recovery potential after surgical resection is maintained by neoplastic transformation of polypotent neuronal stem cells (NSC) discovered in the SVZ $[1,2,3,16]$. The SVZ is located in the lateral wall of the lateral ventricles and is considered as 
the main source of neurogenic cells in mammals. The SVZ consists of four layers, that have different thickness and densities of cells. The deepest layer is represented by ependyma, which lines the ventricular cavity, next is the hypocellular space, then the astrocytic layer and transition zone to white matter. There are four main types of SVZ cells: ependymocytes, NSC, precursors of rapid proliferation and neuroblasts. In addition, endothelial cells, pericytes, microglia, astrocytes and oligodendrocytes presented here. This environment affects the intensity of proliferation and provides signaling between the SVZ components $[1,2,3,16,23]$.

The NSC are located directly in the astrocytic layer of the SVZ, and were not identified in other compartments of the ventricular system (septal wall of the lateral ventricles, the third and fourth ventricles). The NSC pass consequent differentiation stages: migrating progenitors, local progenitors and dedifferentiated glial cells, each could start its glioma population. The migration potential of progenitor cells decreases during this transformation $[1,2,9,14]$.

The similar characteristics between gliomas and the NSC, such as proliferative potential and variant differentiation, mobility, nestin expression and vessel connection, were described. The various studies on animal models had shown the potential origin of gliomas from the SVZ, with oncoming spread along the fibers of the subcortical tracts and loss of communication with the SVZ $[1,2,9,12,14,16]$. The NSC are thought to be responsible for gliomagenesis, resistance to treatment and recurrence. The population of NSC may resuscitate the tumor remains after surgical resection or migrate to start new independent tumors $[2,7,13]$.

In our series, the destructive effect of tumor cell invasion changed the multilayer SVZ structure. The process of tumor invasion involves the sequential activation of various mechanisms of enzymedependent modification of the surrounding extracellular matrix, which creates space for the translocation of neoplastic cells. For PVG cells, there are radial (towards the cortex) and tangential (along the SVZ) types of migration. Also, the invasion into the vascular plexus, ependymal spread and cerebrospinal fluid seeding were described $[3,9,21]$. The glioblastoma contact with the SVZ is a reliable cause of early relapse and progression-free survival shortening after combined therapy $[5,12,13,17,18]$.

Ensuring the maximum cytoreduction of glioblastoma is a factor that significantly affects survival rates in operated patients. Herewith, functionally determined extent of glioblastoma resection requires multimodal approaches for tumor visualization with fluorescent navigation technique and mapping of eloquent structures with electrophysiological monitoring or fiber tracking. These improvements justify the emergence of the concept of supratotal (or supramarginal) resection shifting the extent of tumor removal from the area of contrast enhancement to the FLAIR abnormality zone $[8,10,11,15,20]$.

Based on this position, the surgical planning for resection of PVG puts the width of tumor contact with the ventricular wall into consideration. The invaded ventricular wall should be removed with forming of porencephalia to achieve proper resection volume with survival effect. The presence of porencephalia itself as a result of PVG resection does not correlate with evidence of leptomeningeal tumor dissemination or hydrocephalus, and has no negative effect on survival of operated patients $[5,18]$. 
Previous data suggests that tumor contact with the SVZ affects the type of recurrence. For PVG, the spread recurrence ( $1 \mathrm{~cm}$ around to tumor bed) is four time often than local reoccurrence along tumor bed. For subcortical tumor without SVZ contact, local recurrence was found in $35 \%$ of cases, and spread in $45 \%$. That implies the adjacent SVG is a source of tumor cell, recurrence and/or a factor controlling gliomagenesis $[9,13]$. Therefore, additional resection of the SVZ in surgery of PVG is aimed at eliminating of these sites of gliomagenesis and hidden neoplastic cells migrated along ventricular wall.

The limitations of the study include the lack of prognostic markers data (IDH mutation and MGMT methylation status) for all patients that restricts histopathological correlations of cell invasion potential and tumor aggressiveness. However, the distinctive measurement of tumor cell density and migration distances would provide the guidance for preoperative planning of supratotal resection. Also, ultrastructure changes in the SVZ could fulfill the description of morphological and metabolic features of tumor cells, surrounding structures and characteristics of invasion process. The differentiation of recurrence types related to NSC transformation and direct glioblastoma infiltration of the SVZ requires deeper study using pathomorphological and combined neuroimaging methods. The further controlled trial would help to evaluate the survival benefit of supratotal resection with additional removal of the SVZ or radiosurgery on the SVZ.

\section{Conclusion}

The pathomorphological identification of periventricular glioblastoma invasion in subependymal space supports the supratotal tumor resection with removal of adjacent SVZ as a potential source for relapse.

\section{Declarations}

\section{Funding}

No funding was received for conducting this study.

\section{Conflicts of interest/Competing interests}

The authors have no relevant financial or non-financial interests to disclose.

\section{Availability of data and material}

The data that support the findings of this study are available from the corresponding author upon reasonable request.

Code availability

Not applicable.

\section{Ethics approval}


The study was performed in accordance with the 1964 Helsinki Declaration and approved by the Institutional review board.

Consent to participate

Informed consent was obtained from all individual participants included in the study.

Consent for publication

Not applicable.

Authors' contributions

Conceptualization: Artem Rozumenko, Volodymir Rozumenko;

Methodology: Artem Rozumenko, Valentyn Kliuchka, Tatyana Malysheva;

Formal analysis and investigation: Artem Rozumenko, Valentyn Kliuchka;

Writing - original draft preparation: Artem Rozumenko;

Writing - review and editing: Artem Rozumenko, Valentyn Kliuchka, Alao Oluwateniola;

Resources: Artem Rozumenko, Valentyn Kliuchka, Tatyana Malysheva, Zoja Fedorenko;

Supervision: Volodymir Rozumenko, Tatyana Malysheva

\section{References}

1. Altmann C, Keller S, Schmidt M (2019) The Role of SVZ Stem Cells in Glioblastoma. Cancers 11(4):448

2. Angelucci C, D'Alessio A, Lama G, Binda E, Mangiola A, Vescovi AL, Proietti G, Masuelli L, Bei R, Fazi B, Ciafrè SA, Sica G (2018) Cancer stem cells from peritumoral tissue of glioblastoma multiforme: the possible missing link between tumor development and progression. Oncotarget 9(46):2811628130

3. Barami K, Sloan AE, Rojiani A, Schell MJ, Staller A, Brem S (2009) Relationship of gliomas to the ventricular walls. Journal of clinical neuroscience: official journal of the Neurosurgical Society of Australasia 16(2):195-201

4. Barnholtz-Sloan JS, Ostrom QT, Cote D (2018) Epidemiology of Brain Tumors. Neurol Clin 36(3):395419

5. Behling F, Kaltenstadler M, Noell S, Schittenhelm J, Bender B, Eckert F, Tabatabai G, Tatagiba M, Skardelly M (2017) The Prognostic Impact of Ventricular Opening in Glioblastoma Surgery: A Retrospective Single Center Analysis. World neurosurgery 106:615-624 
6. Bray F, Ferlay J, Soerjomataram I, Siegel RL, Torre LA, Jemal A (2018) Global cancer statistics 2018: GLOBOCAN estimates of incidence and mortality worldwide for 36 cancers in 185 countries. Cancer J Clin 68(6):394-424

7. Chen L, Chaichana KL, Kleinberg L, Ye X, Quinones-Hinojosa A, Redmond K (2015) Glioblastoma recurrence patterns near neural stem cell regions. Radiotherapy and oncology: journal of the European Society for Therapeutic Radiology and Oncology 116(2):294-300

8. Choo J, Takeuchi K, Nagata Y, Ohka F, Kishida Y, Watanabe T, Satoh Y, Nagatani T, Kato K, Wakabayashi T, Natsume A (2018) Neuroendoscopic Cylinder Surgery and 5-Aminolevulinic Acid Photodynamic Diagnosis of Deep-Seated Intracranial Lesions. World neurosurgery 116:e35-e41

9. Dirks PB (2001) Glioma migration: clues from the biology of neural progenitor cells and embryonic CNS cell migration. J Neurooncol 53(2):203-212

10. Esquenazi Y, Friedman E, Liu Z, Zhu JJ, Hsu S, Tandon N (2017) The Survival Advantage of "Supratotal" Resection of Glioblastoma Using Selective Cortical Mapping and the Subpial Technique. Neurosurgery 81(2):275-288

11. Incekara F, Koene S, Vincent A, van den Bent MJ, Smits M (2019) Association Between Supratotal Glioblastoma Resection and Patient Survival: A Systematic Review and Meta-Analysis. World neurosurgery 127:617-624e2

12. Kappadakunnel M, Eskin A, Dong J, Nelson SF, Mischel PS, Liau LM, Ngheimphu P, Lai A, Cloughesy TF, Goldin J, Pope WB (2010) Stem cell associated gene expression in glioblastoma multiforme: relationship to survival and the subventricular zone. J Neurooncol 96(3):359-367

13. Kimura M, Lee Y, Miller R, Castillo M (2013) Glioblastoma multiforme: relationship to subventricular zone and recurrence. The neuroradiology journal 26(5):542-547

14. Lim DA, Cha S, Mayo MC, Chen MH, Keles E, VandenBerg S, Berger MS (2007) Relationship of glioblastoma multiforme to neural stem cell regions predicts invasive and multifocal tumor phenotype. Neurooncology 9(4):424-429

15. Mampre D, Ehresman J, Pinilla-Monsalve G, Osorio M, Olivi A, Quinones-Hinojosa A, Chaichana KL (2018) Extending the resection beyond the contrast-enhancement for glioblastoma: feasibility, efficacy, and outcomes. Br J Neurosurg 32(5):528-535

16. Matarredona ER, Pastor AM (2019) Neural Stem Cells of the Subventricular Zone as the Origin of Human Glioblastoma Stem Cells. Therapeutic Implications Frontiers in oncology 9:779

17. Mistry AM, Dewan MC, White-Dzuro GA, Brinson PR, Weaver KD, Thompson RC, Ihrie RA, Chambless LB (2017) Decreased survival in glioblastomas is specific to contact with the ventricularsubventricular zone, not subgranular zone or corpus callosum. J Neurooncol 132(2):341-349

18. Mistry AM, Kelly PD, Gallant JN, Mummareddy N, Mobley BC, Thompson RC, Chambless LB (2019) Comparative Analysis of Subventricular Zone Glioblastoma Contact and Ventricular Entry During Resection in Predicting Dissemination, Hydrocephalus, and Survival. Neurosurgery 85(5):E924-E932

19. Ostrom QT, Cioffi G, Gittleman H, Patil N, Waite K, Kruchko C, Barnholtz-Sloan JS (2019) CBTRUS Statistical Report: Primary Brain and Other Central Nervous System Tumors Diagnosed in the United 
States in 2012-2016. Neurooncology 21(Suppl 5):v1-v100

20. Pessina F, Navarria P, Cozzi L, Ascolese AM, Simonelli M, Santoro A, Clerici E, Rossi M, Scorsetti M, Bello $L$ (2017) Maximize surgical resection beyond contrast-enhancing boundaries in newly diagnosed glioblastoma multiforme: is it useful and safe? A single institution retrospective experience. J Neurooncol 135(1):129-139

21. Sampetrean O, Saga I, Nakanishi M, Sugihara E, Fukaya R, Onishi N, Osuka S, Akahata M, Kai K, Sugimoto H, Hirao A, Say H (2011) Invasion precedes tumor mass formation in a malignant brain tumor model of genetically modified neural stem cells. Neoplasia 13(9):784-791

22. Siegel RL, Miller KD, Jemal A (2019) Cancer statistics, 2019. Cancer J Clin 69(1):7-34

23. Yoon SJ, Park J, Jang DS et al (2020) Glioblastoma Cellular Origin and the Firework Pattern of Cancer Genesis from the Subventricular Zone. J Korean Neurosurg Soc 63(1):26-33

\section{Figures}

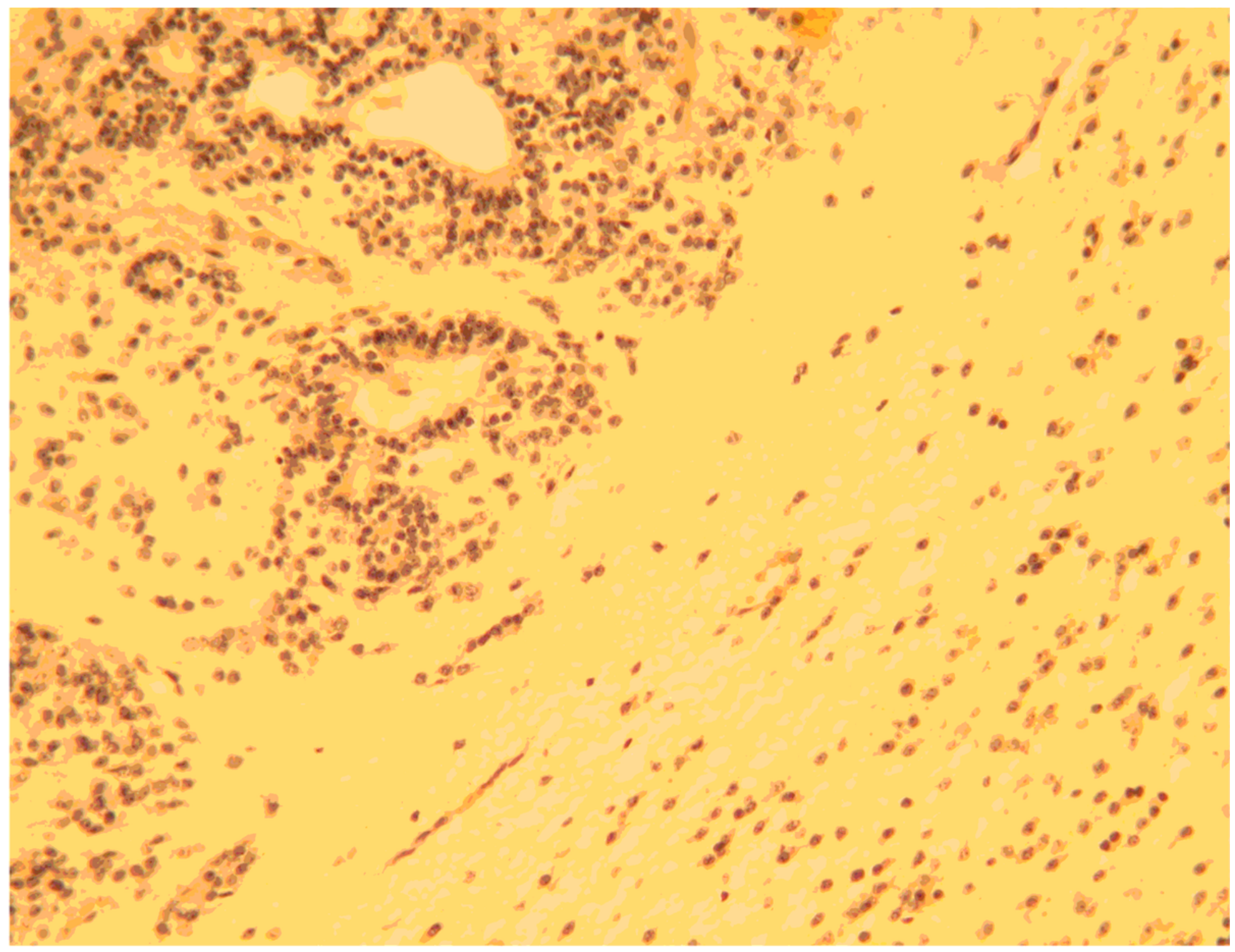


Primitive ependymal rosettes in subependymal area. Hematoxylin - picrofuxin, 200x.

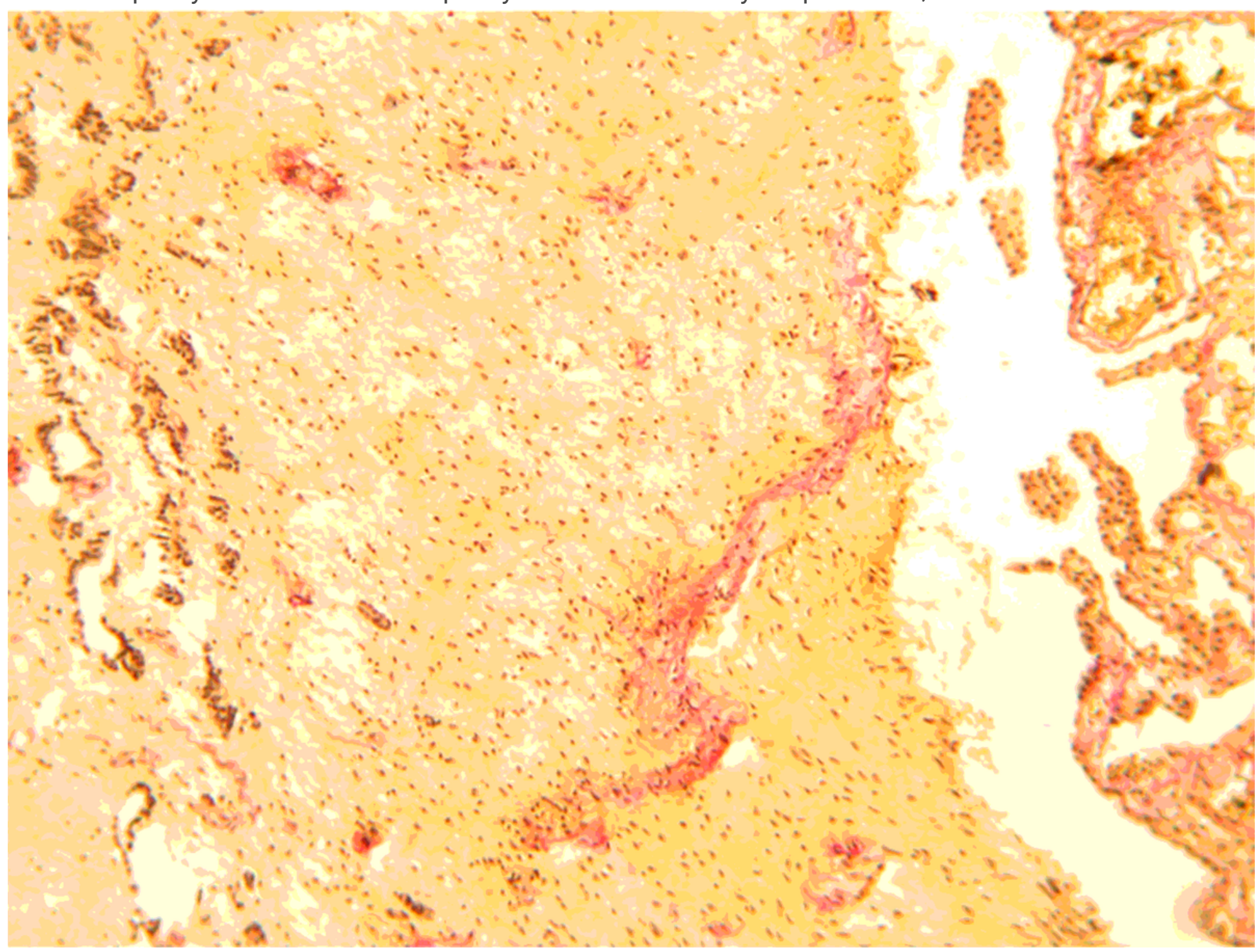

Figure 2

Forming of primitive ependymal rosettes cluster in the subependymal area and vascular plexus. Hematoxylin - picrofuxin, 125x. 

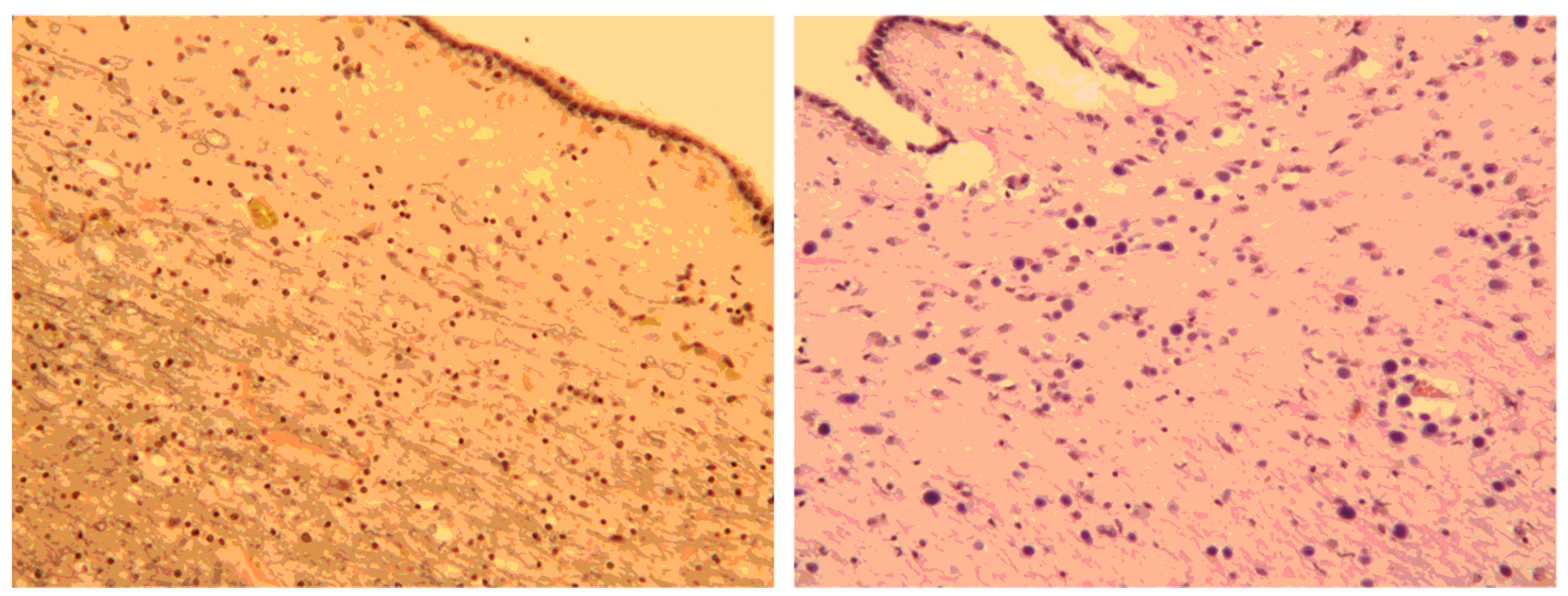

Figure 3

Reactive dystrophic changes of the subependymal white matter: A) Hematoxylin-picrofuxin, 200x. B) Hematoxylin - eosin, 250x.

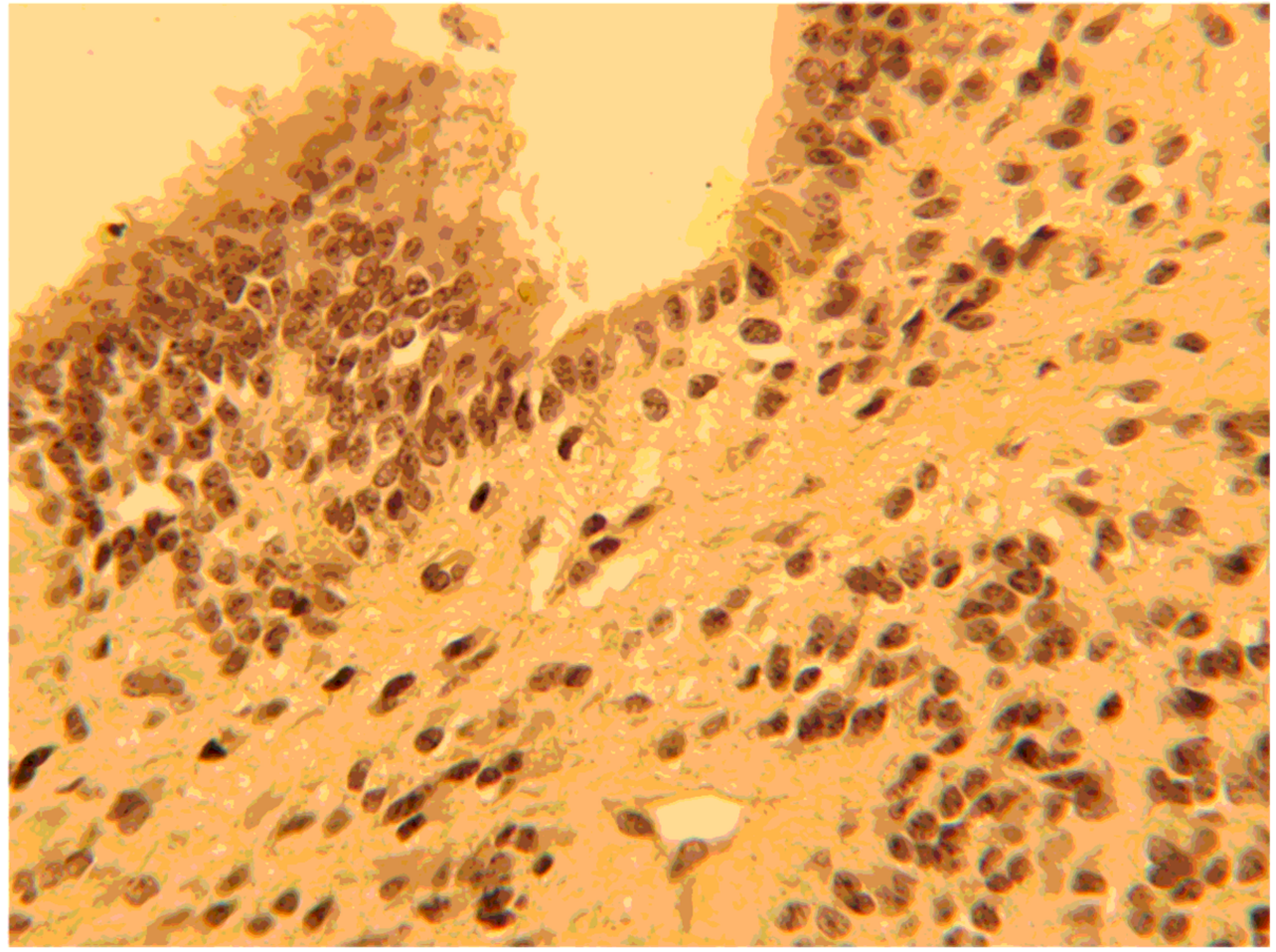


Figure 4

Zone of invasive spread of glioblastoma in the subventricular space. Hematoxylin-picrofuxin, 800x.

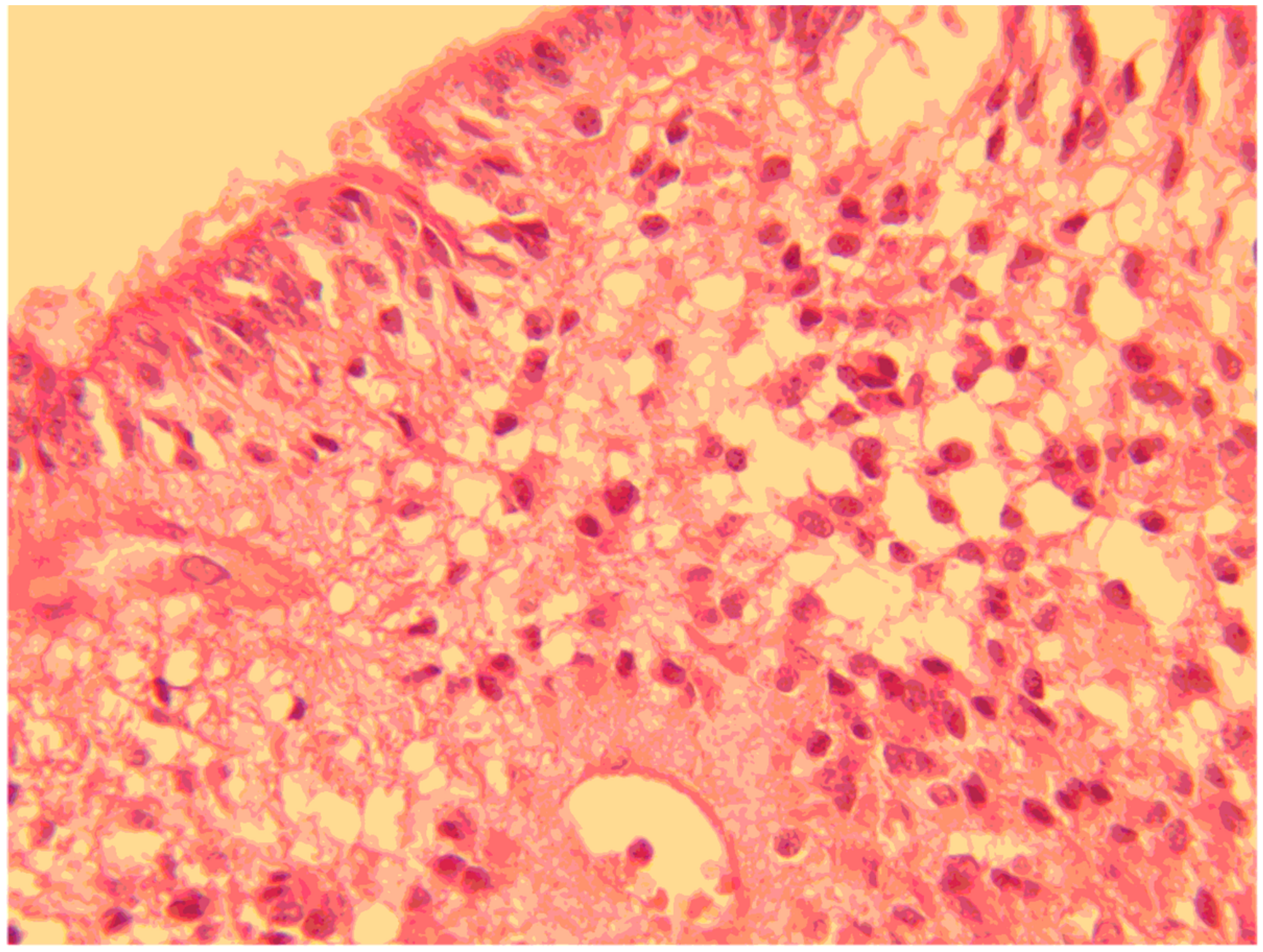

\section{Figure 5}

Zone of invasive spread of glioblastoma in the subventricular space. Hematoxylin-eosin, 800x. 